\title{
Enhancing the magnetic heating capacity of iron oxide nanoparticles through their post-production incorporation into iron oxide-gold nanocomposites
}

\author{
Gavin Bell ${ }^{\star[a, b]}$, Lara K. Bogart ${ }^{[c]}$, Paul Southern ${ }^{[c]}$, Malini Olivo ${ }^{[b]}$, Quentin A. Pankhurst ${ }^{[c]}$ and Ivan P. \\ Parkin*[a]
}

\begin{abstract}
Small variations in the synthesis conditions of iron oxidegold nanocomposites, made in an aqueous medium by a coprecipitation reaction, are found to have a significant effect on the magnetic heating properties of the iron oxide nanoparticles. Citric acid-coated magnetite $\left(\mathrm{Fe}_{3} \mathrm{O}_{4}\right) /$ maghemite $\left(\gamma-\mathrm{Fe}_{2} \mathrm{O}_{3}\right)$ nanoparticles were used as a Turkevich-style reducing agent that was added to varying concentrations of hydrogen tetrachloroaurate trihydrate $\left(\mathrm{HAuCl}_{4}\right)$, resulting in iron oxide-gold nanoparticle composites with Fe:Au molar ratios ranging from ca. 5:1 to ca. 300:1. The magnetic heating capacity of the products was measured in a high frequency alternating field (peak amplitude $6.6 \mathrm{kA} / \mathrm{m}$, frequency $967 \mathrm{kHz}$ ), to determine both the specific absorption rate (SAR) and intrinsic loss power (ILP) parameters of the products. The iron oxide precursor presented a moderately high SAR of $33.9 \mathrm{~W} / \mathrm{g}_{\mathrm{FeO}}$ and ILP of $0.8 \mathrm{nHm}^{2} / \mathrm{kg}_{\mathrm{FeO}}$, but the iron oxide-gold nanocomposite formed with $0.75 \mathrm{mM} \mathrm{HAuCl}_{4}$ had an almost threefold-enhanced heating capacity, with a SAR of $88.3 \mathrm{~W} / \mathrm{g}_{\mathrm{FeOx}}$ and an ILP of $2.1 \mathrm{nHm}^{2} / \mathrm{kg}_{\mathrm{FeOx}}$. This result has implications for the possible post-production enhancement of the magnetic heating capacity of similar iron oxide systems, as well as raising the theranostic potential of such materials through the incorporation of Au nanoparticles that may act as integrated binding sites for drugs or other beneficial biomolecules.
\end{abstract}

\section{Introduction}

The high intrinsic magnetisation at room temperature of the ferrimagnetic iron oxides magnetite $\left(\mathrm{Fe}_{3} \mathrm{O}_{4}\right)$ and maghemite $(\gamma$ $\mathrm{Fe}_{2} \mathrm{O}_{3}$ ) has led to their extensive use in many technological applications, from the ubiquitous fridge magnet through to highperformance components in transformers and engines. However, these particular iron oxides are also biocompatible, which has led to their being used in their fine particle (superparamagnetic) form for clinical applications for more than 20 years. ${ }^{[1]}$ Over the last ten years there has been a significant increase in the exploration of magnetite and/or maghemite nanoparticles for a wide range of

[a] Materials Chemistry Research Centre, Department of Chemistry, University College London, 20 Gordon Street, London, WC1H 0AJ, UK

E-maili.i.p.parkin@ucl.ac.uk

https://www.ucl.ac.uk/chemistry/people/ivan-parkin

E-mail:Gavin Bell@sbic.ac.uk

[b] Bio-Optical Imaging Group, Singapore Bio-Imaging Consortium (SBIC), Agency for Science Technology and Research ( $\left.A^{*} S T A R\right)$, Helios \#01-02, 11 Biopolis Way, Singapore, 138667

[c] Healthcare Biomagnetics Laboratory, University College London, 21 Albemarle Street, London, WS1 4BS, UK

Supporting information for this article is given via a link at the end of the document. novel biomedical devices and treatments, from drug delivery and magnetic separation through to magnetic resonance imaging (MRI) contrast agents and magnetic hyperthermia. ${ }^{[2-5]}$ In addition, novel nanostructures such as these may possess translatable benefits in biomedicine, including such unique nanocomposites being developed as gene transfer agents and for stem cell tracking. This allows for noninvasive monitoring and analysis of stem cells within a biological system ${ }^{[6-9]}$

The formation of capped nanoparticles is also of current interest, as capping agents can offer stability and protection against excessive aggregation which can disrupt the desired properties of the particles. These capping agents include organic polymers ${ }^{[10-12]}$, inorganic coatings ${ }^{[13-15]}$ and metallic shells. Regarding the latter, gold coated iron oxide nanoparticles ${ }^{[16-19]}$ are of particular interest as they have the potential to open up facile routes to covalently bond ligands to the nanoparticles (via the capping agent), based on the affinity that gold has to thiols. There is also the potential for a gold coating to reduce the degradation for the iron oxide caused by oxidation of magnetite to maghemite - albeit that this relies on the formation of a contiguous coating around the entire particle, which is difficult to achieve given the surface energies at play. ${ }^{\text {20] }}$

Nevertheless, even without a fully-formed encapsulating shell, the co-existence of gold and iron oxide nanoparticles in an intimately mixed composite is itself of potential value, both in providing a route to enhanced biocompatibility and functionality, and in terms of the possible multimodal or theranostic applications. For example, iron oxide has been routinely used as a magnetic resonance imaging contrast agent for several decades ${ }^{[1]}$ and, more recently, it has been used in magnetic particle imaging; ${ }^{[21]}$ while the addition of gold could enable additional imaging modalities such as optical spectroscopy, surface plasmon resonance, surface enhanced Raman spectroscopy and photoacoustic spectroscopy. As such, iron oxide-gold nanocomposites could potentially act as a multimodal imaging platform that might have many different uses.

From a theranostic perspective, another attractive possibility is to harness the therapeutic potential of one or other (or both) of the materials in the composite. For both gold and iron oxide nanoparticles, attention to date has focused on the heat generation phenomena that may be elicited when the nanoparticles are placed in a rapidly time-varying magnetic (for iron oxide) or electromagnetic (for gold) field. The principle here is to achieve a new targeted route to the long-established therapeutic practice of clinical hyperthermia - wherein tissue is heated to ca. $40^{\circ}$ to $44^{\circ} \mathrm{C}$, at which point it is known that certain pathogens, including many cancer cell types, are more affected than are heathy cells, rendering them more susceptible to adjuvant treatments such as chemotherapy and radiotherapy. ${ }^{[12]}$ 
In this context, for superparamagnetic magnetite or maghemite nanoparticles, it has been found that if they are placed in an alternating magnetic field of sufficient strength (viz. amplitude $H \approx 5 \mathrm{kA} / \mathrm{m}$ or above) operating at an appropriate frequency (viz. the low radio frequency range, $f \approx 100 \mathrm{kHz}$ to 1.5 $\mathrm{MHz}$ ), they can generate heat $P=\mu_{0} \pi f \chi^{\prime \prime} H^{2}$, where $\chi^{\prime \prime}$ is the outof-phase magnetic susceptibility, a measure of the 'lag' between the driving field and the magnetisation of the particle. ${ }^{[2]}$ The heat thus generated is quantified in terms of the effective specific absorption rate (SAR) parameter - which clinically describes the power dissipation in watts per gram of tissue, but which in the scientific literature is most often defined as the power dissipation in watts per gram of the heating material - and in more precise technical terms by the intrinsic loss power (ILP) parameter, where $\mathrm{ILP} \approx \mathrm{SAR} / H^{2} f{ }^{\left[{ }^{[22-24]}\right.}$ As a rule of thumb, a good quality magnetic heating iron oxide nanoparticle will exhibit an ILP in the range 1 to $3 \mathrm{nHm}^{2} / \mathrm{kg}_{\mathrm{FeOx}}$, which at $H=5 \mathrm{kA} / \mathrm{m}$ and $f=1 \mathrm{MHz}$ corresponds to SAR values of order 25 to $75 \mathrm{~W} / \mathrm{g}_{\mathrm{FeO}}$.

The situation for gold nanoparticles is different, with the heat generation effects being observed in electromagnetic fields in the high radio frequency and low microwave frequency region (e.g. at the microwave industry standard $13.56 \mathrm{GHz}$ band), and with the heating mechanism being rather less well understood to date. ${ }^{[25]}$ There has also been considerable debate in the literature over the SAR values achievable using gold nanoparticles, with early experimental reports of enormous values (ca. 300,000 $\left.\mathrm{W} / \mathrm{g}_{\text {sample }}\right)^{[26]}$ being later repeated and producing much more modest values (ca. $2 \mathrm{~W} / \mathrm{g}_{\text {sample, }}$, corresponding to ca. $1 \mathrm{~W} / \mathrm{g}_{\mathrm{Au}}$ ). ${ }^{[27]}$ However, a consensus appears to be emerging, with the earlier values being tentatively ascribed to artefacts associated with saline excipients, ${ }^{[25]}$ and reliable SAR values of order $9 \mathrm{~W} / \mathrm{g}_{\text {sample }}$ (corresponding to ca. $6 \mathrm{~W} / \mathrm{g}_{\mathrm{Au}}$ ) being achieved. ${ }^{[28]}$ It is also notable that the heating effects are thought to be real only in gold nanoparticles smaller than $10 \mathrm{~nm}$ in diameter. ${ }^{[25]}$

In light of these considerations, we report here on a study in which we have explored the effect on the magnetic heating properties of iron oxide nanoparticles of their incorporation into iron oxide-gold nanocomposites. In a novel procedure, we have adapted the 1950s-vintage Turkevich synthesis of gold nanoparticles ${ }^{[29]}$ by using previously-synthesised citrate-coated iron oxide nanoparticles as a reducing agent to transform $\mathrm{HAuCl}_{4}$ into $\mathrm{Au}$. The resultant products are found to form a well-defined series of nanocomposites in which the gold nanoparticles increase in size consistently in proportion to the $\mathrm{HAuCl}_{4}$ concentration used during synthesis, while the iron oxide nanoparticles seem to largely retain the size and magnetic characteristics of the original phase. In an unexpected but significant result we find that the presence of the gold leads to a marked enhancement of the magnetic heating capacity of the particles, as evidenced by a threefold increase in the measured SAR/ILP parameter, under optimum conditions.

\section{Results and Discussion}

\section{Synthesis}

All iron oxide nanoparticles were synthesised via the coprecipitation method, where ferric and ferrous chloride salts were aqueously dissolved, heated and reduced with ammonium

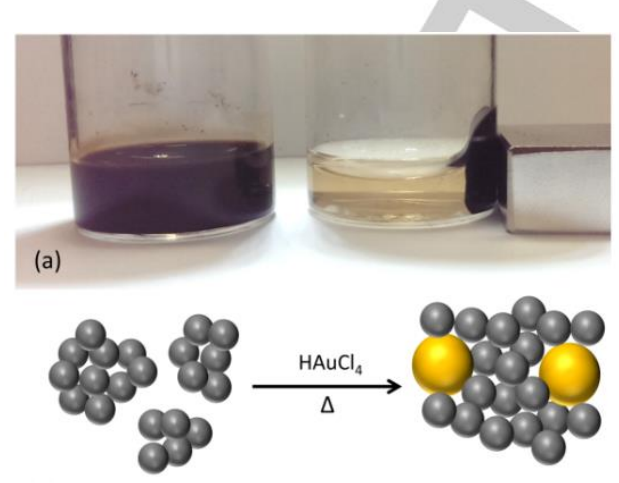

(b)

Figure 1. (a) Photograph showing the citric acid stabilised ferrofluid IO-C with and without the influence of an external magnetic field. In the absence of the magnetic field the ferrofluid forms a stable suspension in water. (b) Graphic showing the morphology of the FeOx-Au aggregates formed from hydrogen tetrachloroaurate reduction by citrate capped iron oxide nanoparticles.

hydroxide alongside a stabilising ligand of citric acid. These citrate-coated iron oxide nanoparticles were then isolated as an aqueous ferrofluid and classified as FeOx-C. Further functionalisation was achieved with hydrogen tetrachloroaurate of varying concentrations and hence classified as $\mathrm{FeOx}-\mathrm{Au}_{x}$ where $x$ represents the synthetic hydrogen tetrachloroaurate concentration in $\mathrm{mM}$. All products were then readily dispersible in water and formed strong ferrofluids (Figure 1).

\section{Structural characterisation of the precursor iron oxide nanoparticles}

Figure 2 shows TEM, UV-Vis and IR data for the as-prepared citrate-coated iron oxide nanoparticles (FeOx-C). Electron
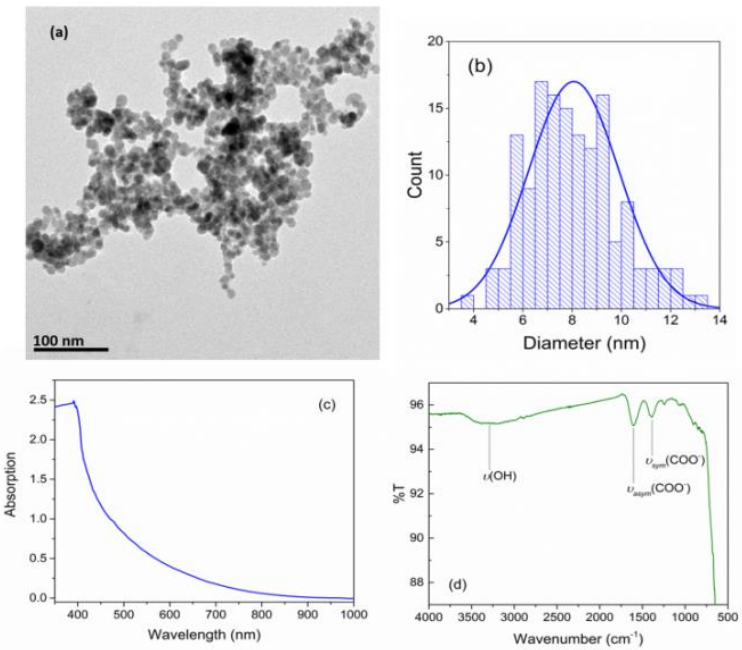
Figure 2. (a) Transmission electron micrograph of the as-made citrate-coated iron oxide nanoparticles; (b) the TEM-derived size distribution histogram for the inorganic cores; (c) the UV-vis spectrum of the sample; and (d) the FT-IR spectrum showing the presence of the carboxyl functional groups in the citric acid

microscopy shows largely spherical particles with an average core diameter of $8.0 \mathrm{~nm}$ and standard deviation of $1.8 \mathrm{~nm}$. This size distribution (of 147 particles) shows some polydispersity, which is common with co-precipitation reaction schemes. UV-Vis spectra shows a smooth absorption curve with a decrease in absorption at longer wavelengths. Dynamic light scattering (DLS) measurements showed a hydrodynamic diameter $\varphi_{H}$ of ca. 252 $\mathrm{nm}$ when measured via intensity and a polydispersity index (PDI) of 0.27 . The much larger value for the diameter than that given by TEM reflects the contributions to the hydrodynamic radius of the particles, which includes both the citrate coating on the nanoparticle surface and the overall solvation layer around the particles. The large hydrodynamic diameter might also indicate some degree of aggregation resulting in larger effective particle diameters.

FT-IR measurements show the presence of both an $v(\mathrm{OH})$ vibration at $3315 \mathrm{~cm}^{-1}$ and $v_{\text {sym }}(\mathrm{COO}-)$ and $v_{\text {asym }}(\mathrm{COO}-)$
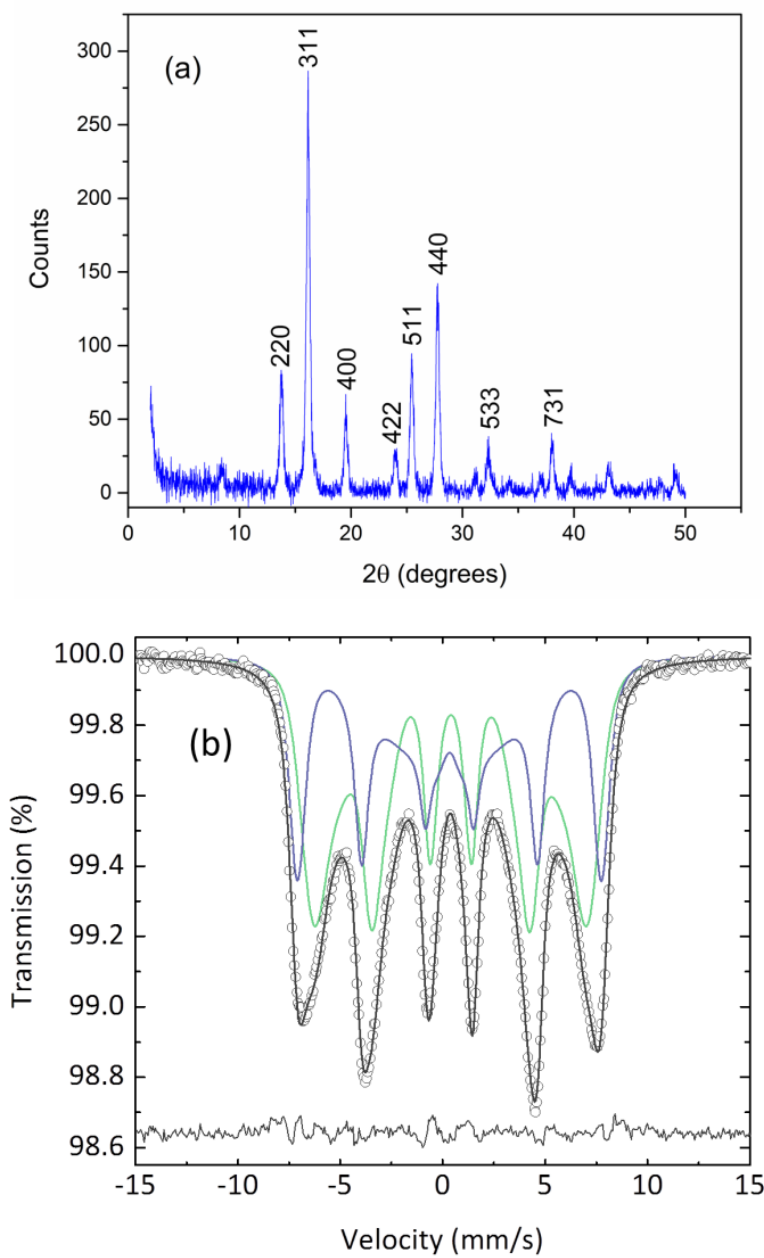

Figure 3. (a) Mo- $\mathrm{K}_{a} \theta-2 \theta$ powder diffraction pattern of $\mathrm{FeOx}-\mathrm{C}$ nanoparticles, indexed against a cubic lattice. (b) Room temperature Mössbauer spectrum of the as-prepared citrate-coated iron oxide nanoparticles (FeOx-C) sample. The best fit to the observed spectrum was obtained using two Voigtian sextets, each comprising two sub-component spectra. The residual between the observed data and the model is indicated by the lower trace.

vibrations (1661 $\mathrm{cm}^{-1}$ and $1394 \mathrm{~cm}^{-1}$, respectively), which confirms the presence of the carboxyl functional groups present in citric acid. The measured values are shifted to a lower frequency than what would be expected from a free carboxylate group, which indicates coordination of the citric acid to the iron oxide through the carboxylic groups.

X-ray diffraction data were consistent with the FeOx-C samples being an iron oxide with a cubic structure (Figure 3a), with the main peaks being able to be indexed against the magnetite powder diffraction file at International Centre for Diffraction Data (ICDD). However, it should be noted that it can be difficult to distinguish between the X-ray diffraction patterns of magnetite and maghemite, particularly when they are in their nanoparticulate state ${ }^{\left[{ }^{[0]}\right.}$ and as such this assignment should be regarded as tentative. In any case, the mean crystallite size was determined using the Scherrer equation of the (311) peak indicating a mean iron oxide crystallite size of order 8-10 nm (Table 1). This is in agreement with TEM data (see below) which showed a comparable average diameter of 8-9 $\mathrm{nm}$ for the iron oxide cores. From this we conclude that each core is monocrystalline.

Room temperature Mössbauer spectroscopy (Figure 3b) of the as-prepared material shows the distinctive six line absorption pattern that is characteristic of magnetic hyperfine splitting, and of the magnetite/maghemite series of iron oxides. The best fit to the spectrum was obtained using Voigtian line profiles, following the quasi-phenomenological model recently described for fitting the Mössbauer spectra of magnetite/maghemite mixtures or solid solutions. ${ }^{[31]}$ Voigtian line-shapes are used to represent a Gaussian distribution of hyperfine fields, which may arise from crystallographic impurities, a range of sizes and shapes, the presence of collective excitations, or a combination of each of these factors.

The cumulative mean isomer shift or centre of gravity of the spectrum (i.e. the average over all the contributing subcomponent spectra) was determined to be $\bar{\delta}_{R T}=0.37 \pm 0.01 \mathrm{~mm} / \mathrm{s}$, which lies between that of pure maghemite $\left(\bar{\delta}_{R T}=0.32 \mathrm{~mm} / \mathrm{s}\right)$ and pure magnetite $\left(\bar{\delta}_{R T}=0.53 \mathrm{~mm} / \mathrm{s}\right)$. Given that it is more likely that the material is a mixture of phases than for it to be a solid solution the latter being more characteristic of bulk systems, while the former is known to be a characteristic of fine particle magnetite/maghemite systems ${ }^{[32]}$ - we can use the $\bar{\delta}_{R T}$ measurement to estimate the composition of the mixture. Following an established procedure, ${ }^{[32,33]} \bar{\delta}_{R T}=0.37 \pm$ $0.01 \mathrm{~mm} / \mathrm{s}$ equates to a magnetite content of $23 \% \pm 5 \% \mathrm{w} / \mathrm{w}-$ meaning that $23 \pm 5 \mathrm{wt} . \%$ of the as-prepared iron oxide is in the form of magnetite, and the remaining $77 \pm 5 \mathrm{wt}$. $\%$ is in the form of maghemite.

Having thus estimated the composition of the precursor FeOx-C nanoparticles, the composition of the as-prepared FeOx- 
$\mathrm{Au}_{x}$ samples can also now be estimated. Table 2 shows the results of such calculations across the series for both the molar ratio of $\mathrm{Fe}$ to $\mathrm{Au}$ (derived from the molecular weights of magnetite, maghemite and gold), and for the volume ratio of iron oxide to gold (using textbook data on the densities of bulk magnetite, maghemite and gold).

Table 1. Crystallite sizes and gold concentrations of synthesis of iron oxide and iron oxide - gold nanocomposite particles determined via PXRD and TEM.

\begin{tabular}{cccccc}
\hline & & \multicolumn{2}{c}{$\begin{array}{c}\text { XRD Crystallite } \\
\text { Diameter }(\mathrm{nm})\end{array}$} & \multicolumn{2}{c}{$\begin{array}{c}\text { TEM } \\
\text { Diameter }(\mathrm{nm})\end{array}$} \\
\cline { 3 - 6 } & {$[\mathrm{Au}](\mathrm{mM})$} & $\mathrm{FeOx}$ & $\mathrm{Au}$ & $\mathrm{FeOx}$ & $\mathrm{Au}$ \\
\hline FeOx-C & 0 & $9 \pm 1$ & - & $8 \pm 2$ & - \\
FeOx-Au0,25 & 0.25 & $8 \pm 1$ & $19 \pm 1$ & $8 \pm 2$ & $25 \pm 5$ \\
FeOx-Aun 0,75 & 0.75 & $10 \pm 1$ & $15 \pm 1$ & $9 \pm 2$ & $35 \pm 8$ \\
FeOx-Au & 1.0 & $9 \pm 1$ & $11 \pm 1$ & $8 \pm 2$ & $56 \pm 22$ \\
\hline
\end{tabular}

\section{Structural characterisation of iron oxide - gold nanocomposites}

Transmission electron microscopy was performed on the majority of the FeOx-Aux series of samples to evaluate the morphological changes as a function of the addition of Au to the nanocomposite mixtures. Representative TEM micrographs illustrating these changes are shown in Figure 4, and the corresponding particle size histograms are shown in Figure 5.

As may have been anticipated given that the $\mathrm{FeOx}$ nanoparticles are effectively a substrate carrying the reducing reagent in the Au synthesis reaction, both their mean size and polydispersity is largely unchanged over the series. However, the Au nanoparticles exhibit a steady growth across the series, with larger and increasingly polydisperse collections of particles appearing as the $\mathrm{HAuCl}_{4}$ concentration increased (Figure 5). It is intriguing to note that the polydispersity in the Au nanoparticle size distribution appears to increase suddenly at and above $\left[\mathrm{HAuCl}_{4}\right]$ $=1.0 \mathrm{mM}$.

Another feature evident in the TEM data is that the FeOx nanoparticles seem to appear to be aggregating around the surrounding Au nanoparticles. Such agglomeration might possibly be an induced feature relating to the way in which the TEM grid samples were prepared. However, DLS data on selected FeOx$A u_{x}$ samples - albeit being difficult to interpret with accuracy given the presence of two phases with significantly different scattering cross-sections and sizes - indicated that the particles were agglomerated in situ, with Z-average hydrodynamic diameters $\varphi_{H}$ of order $270 \mathrm{~nm}$ in FeOx-Au 0.75 and $960 \mathrm{~nm}$ in FeOx-Au $\mathrm{Au}_{5.0}$, both with PDI's of order 0.3. Thus it appears to be possible that the nanocomposites are forming physically congruent aggregages/agglomerates during synthesis that are persisting thereafter.

These iron oxide-gold aggregates do not form in an organised and aligned structure, as can be seen from the TEM images (Figure 4). There is a somewhat random post-production of gold nanoparticles throughout the nanomaterial. However iron oxide nanoparticles can be used to form well defined aligned biomolecules when subject to an aligned static external magnetic field. ${ }^{[34]}$ Here, we synthesised spherical nanoparticles that when under an aligned field would not form an oriented structure but an isometric pattern. It may be desirable to attach

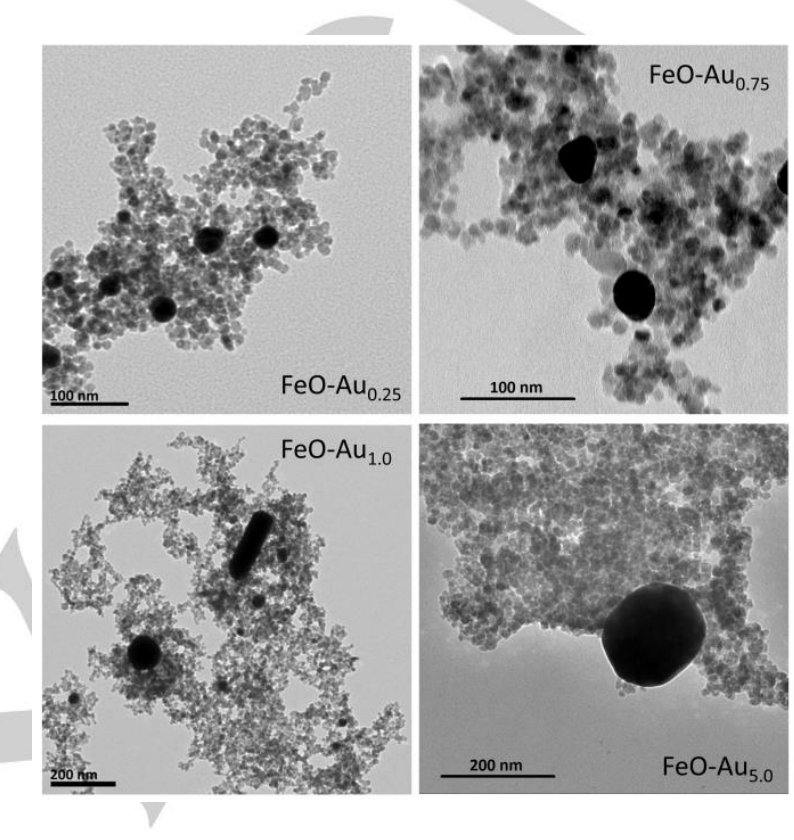

Figure 4. Representative TEM images of a selection of $\mathrm{FeOx}-\mathrm{Au}_{x}$ iron oxidegold nanocomposites, showing that the Au nanoparticles increase in size as the molar concentration increases, and that the iron oxide nanoparticles form aggregates surrounding the gold nanoparticles. 

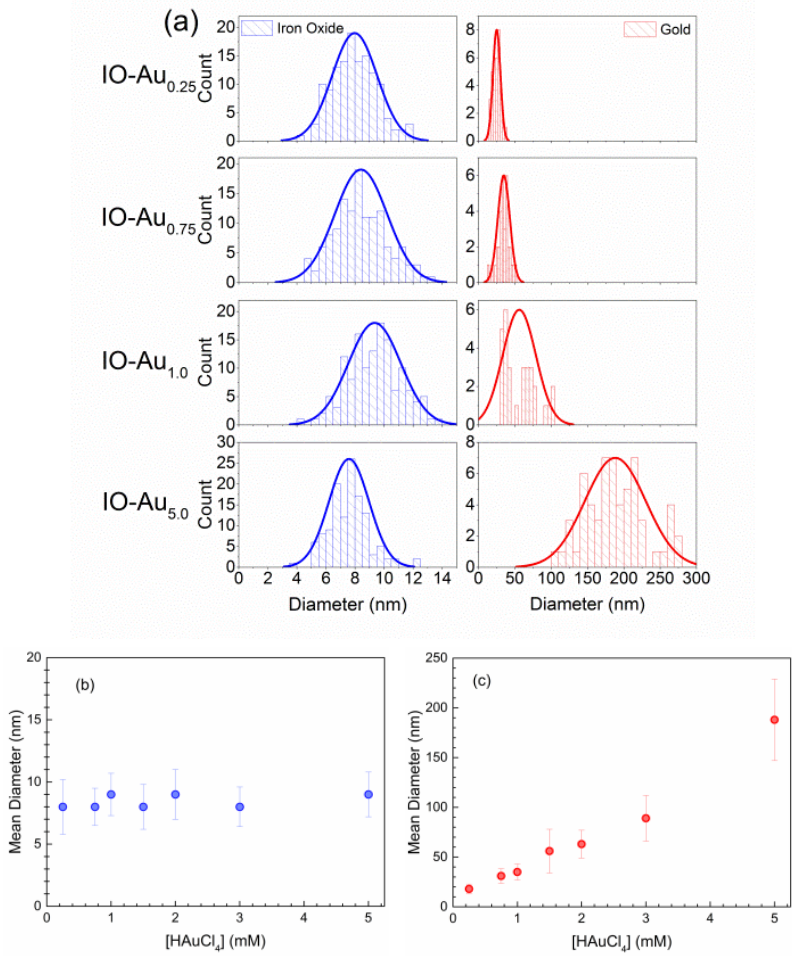

Figure 5. (a) Particle size distribution histograms derived from TEM data such as that shown in Figure 4 for a selection of $\mathrm{FeOx}-\mathrm{Au}_{x}$ iron oxide-gold nanocomposites. (b) Means and standard deviations of the iron oxide and (c) the gold particles as a function of the $\mathrm{HAuCl}_{4}$ concentration used during synthesis. Note that both the mean size and the polydispersity of the gold nanoparticles changes significantly over the series, while the iron oxide nanoparticles remain largely unaltered. crystallinity, and poor reflection coherence. There is also evidently some concentration-dependent variation in the crystallinity of the Au nanoparticles, as seen by the relatively poor definition of the gold (111) peak in FeOx-Au $u_{0.75}$ compared to that seen in either $\mathrm{FeOx}-\mathrm{Au}_{0.25}$ or $\mathrm{FeOx}-\mathrm{Au}_{1.0}$. However, the underlying phases do not appear to be affected, as illustrated by there being no shift across the series in either the (311) iron oxide or the (111) gold peak positions.

The crystallite size for the Au nanoparticles was calculated from the X-ray data, using the Scherrer equation applied to the gold (111) peak at $2 \theta=17.3^{\circ}$. This analysis yielded crystallite size ranging from ca. $19 \mathrm{~nm}$ for $\mathrm{FeOx}-\mathrm{Au}_{0.25}$ to $11 \mathrm{~nm}$ for $\mathrm{FeOx}-\mathrm{Au}_{1.0}$ (see Table 1). These are significantly smaller than the diameters obtained from the TEM data (ca. $25 \mathrm{~nm}$ and $56 \mathrm{~nm}$ for FeO-Au $\mathrm{u}_{0.25}$ and $\mathrm{FeO}-\mathrm{Au}_{1.0}$ respectively), which again indicates that the individual gold nanoparticles are polycrystalline.

\section{UV-vis, XPS and Mössbauer spectroscopy measurements}

UV-vis spectra reflected the growth of larger gold nanoparticles at higher $\mathrm{HAuCl}_{4}$ concentrations, as evidenced by the gold plasmon peak being red-shifted to higher absorption wavelengths for larger particles. The shift in peak position is shown in Figure 7, from 516 $\mathrm{nm}(0.25 \mathrm{mM})$, to $526 \mathrm{~nm}(0.75 \mathrm{mM})$, and $556 \mathrm{~nm}(1.0 \mathrm{mM})$, as the concentration increases.

XPS spectra showed that within the $\mathrm{FeOx}-\mathrm{Au}_{x}$ series the scattering peaks for the carbon $1 \mathrm{~s}$ electrons at $285 \mathrm{eV}$, oxygen $1 \mathrm{~s}$ electrons at $530 \mathrm{eV}$ and iron $2 \mathrm{p}$ electrons at $710 \mathrm{eV}$ were all present. The Fe2p electrons are exclusively from the nanoparticles, whereas the O1s electrons are present in both the nanoparticles and the citrate stabilising ligands. The Fe2p atomic \% of the FeOx nanoparticles was classified as $15 \%$, showing that a large proportion of the sample is comprised of the citrate ligands.

Table 2. Derived parameters for the as-made $\mathrm{FeOx}-\mathrm{Au}_{\mathrm{x}}$ iron oxide-gold nanocomposites as a function of the concentration of $\mathrm{HAuCl} 4 \mathrm{used}$ in the synthesis process: the molar ratio of $\mathrm{Fe}$ to $\mathrm{Au}$ atoms, and the volume ratio of iron oxide to gold, in the products.

\begin{tabular}{|c|c|c|c|c|c|c|c|c|c|c|c|}
\hline Sample & $\begin{array}{c}\mathrm{FeOx}- \\
\mathrm{Au}_{0.1}\end{array}$ & $\begin{array}{l}\mathrm{FeOx}- \\
\mathrm{Au}_{0.25}\end{array}$ & $\begin{array}{c}\mathrm{FeOx}- \\
\mathrm{Au}_{0.4}\end{array}$ & $\begin{array}{c}\mathrm{FeOx} \\
\mathrm{Au}_{0.5}\end{array}$ & $\begin{array}{c}\mathrm{FeOx}- \\
\mathrm{Au}_{0.6}\end{array}$ & $\begin{array}{l}\mathrm{FeOx}- \\
\mathrm{Au}_{0.75}\end{array}$ & $\begin{array}{c}\mathrm{FeOx}^{-} \\
\mathrm{Au}_{1.0}\end{array}$ & $\begin{array}{c}\mathrm{FeOx}- \\
\mathrm{Au}_{1.5}\end{array}$ & $\begin{array}{c}\mathrm{FeOx}- \\
\mathrm{Au}_{2.0}\end{array}$ & $\begin{array}{c}\mathrm{FeOx}- \\
\mathrm{Au}_{3.0}\end{array}$ & $\begin{array}{r}\mathrm{FeOx}- \\
\mathrm{Au}_{5.0}\end{array}$ \\
\hline $\begin{array}{c}{\left[\mathrm{HAuCl}_{4}\right]} \\
(\mathrm{mM})\end{array}$ & 0.1 & 0.25 & 0.4 & 0.5 & 0.6 & 0,75 & 1.0 & 1.5 & 2.0 & 3.0 & 5.0 \\
\hline $\begin{array}{l}\text { Molar } \\
\text { Ratio } \\
\text { Fe/Au }\end{array}$ & 316 & 126 & 79 & 63 & 53 & 42 & 32 & 21 & 16 & 11 & 6 \\
\hline $\begin{array}{c}\text { Vol. } \\
\text { Ratio } \\
\mathrm{FeO}_{x} / \mathrm{Au}\end{array}$ & 490 & 196 & 122 & 98 & 82 & 65 & 49 & 33 & 24 & 16 & 10 \\
\hline
\end{tabular}

the iron oxide -gold aggregates to oriented biomolecules to further increase the biological impact.

Powder X-ray diffraction data from selected $\mathrm{FeOx}-\mathrm{Au}_{\mathrm{x}}$ samples are shown in Figure 6. Diffraction peaks due to both the $\mathrm{FeOx}$ and $\mathrm{Au}$ phases are present, albeit the signal to noise ratio is worse than was observed for the FeOx-C sample (Figure 3). This may be attributed to the presence of the Au nanoparticles, as gold is known to grow unevenly when forming nanoparticles and coatings, which can result in a coarse texture, variable
Within the $\mathrm{FeOx}-\mathrm{Au}_{\mathrm{x}}$ samples, two gold environments were seen: $A u 4 f 7 / 2$ and $A u 4 f 5 / 2$ at 84.3 and 88.1 eV respectively, representing ca. 1 at.\% gold. A depth profile was performed which showed no change in the gold spectrum, signifying the formation of iron oxide - gold nanoparticle aggregates rather than core-shell nanoparticles, for which different XPS characteristics and size distribution histograms where there has been no change on the FeOx particle diameters as the gold concentration varies. 

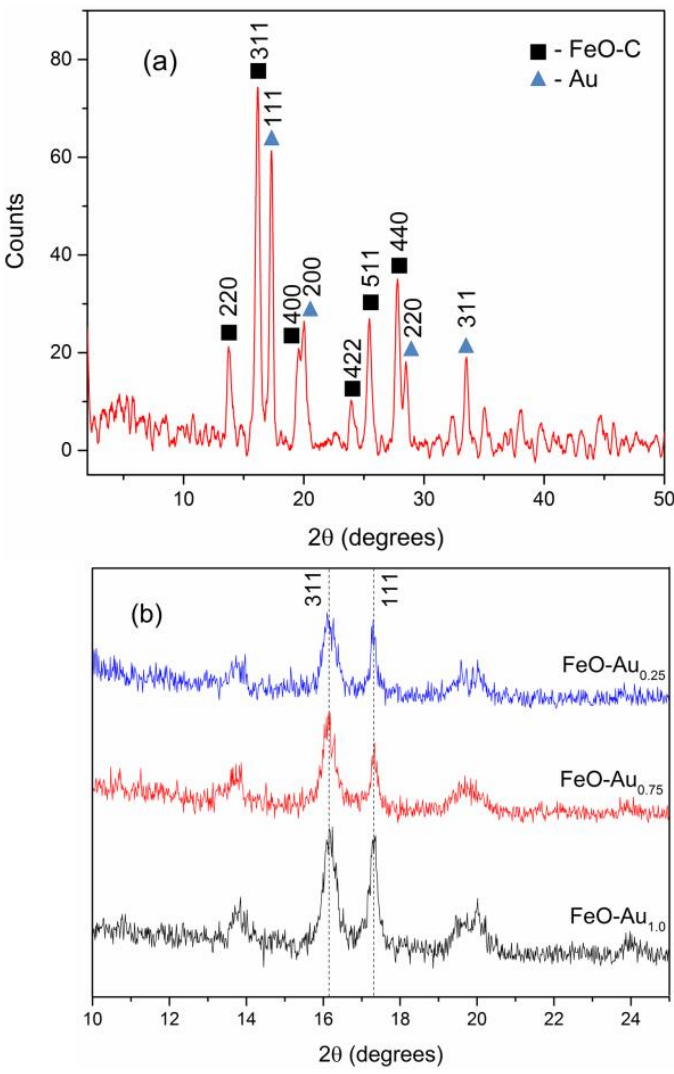

Figure 6. Mo-Ka $\theta-2 \theta$ powder diffraction patterns of FeOx-Au nanocomposites showing (a) the $\mathrm{FeOx}$ and $\mathrm{Au}$ reflections in the $\mathrm{FeOx}-\mathrm{Au}_{0.75}$ sample; and (b) the coincidence of the (311) iron oxide and (111) gold diffraction peak positions across the $\mathrm{FeOx}-\mathrm{Au}_{x}$ series.

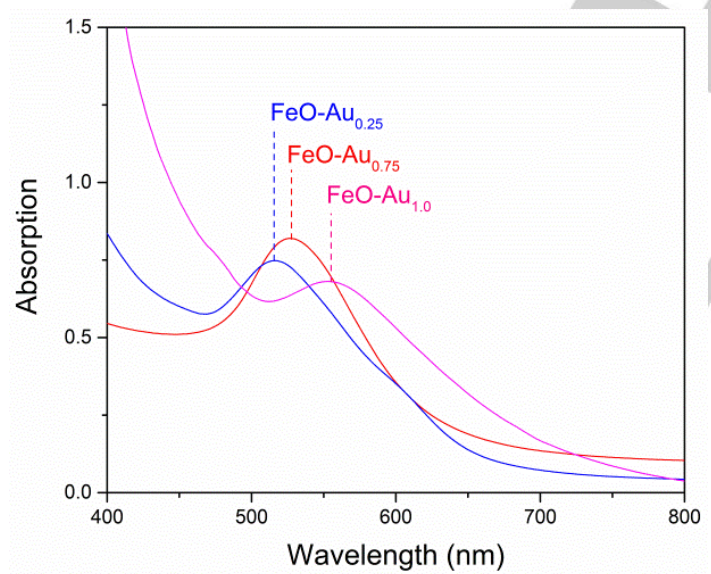

Figure 7. UV-vis spectra of FeOx-Aux samples with $x=0.25,0.75$ and $1.0 \mathrm{mM}$, showing the red shift in the gold absorption peak as the Au concentration increased.

Room temperature ${ }^{57} \mathrm{Fe}$ Mössbauer spectra were recorded across the FeOx-Aux series, as shown in Figure 8(a). For the lower concentrations of gold $(x=0.1 \mathrm{mM}$ to $0.75 \mathrm{mM})$, the spectrum becomes increasingly broad in the central portion of the spectrum, although there is no collapse of the innermost lines. In addition, the outermost lines become increasingly asymmetric and there is a corresponding loss of intensity. Interestingly, as more gold is added to the FeOx nanoparticles $(x>1.0 \mathrm{mM})$, the spectrum begins to recover its original shape and by $x=5 \mathrm{mM}$ it looks very much like that of $\mathrm{FeOx}-\mathrm{C}$, i.e., before the addition of any gold. To help visualise these trends, Figure $8(\mathrm{~b})$ shows the difference spectra obtained by subtracting a normalised FeOx-C $(x=0)$ spectrum from the $x \geq 0$ spectrum. This procedure allows us to clearly observe the progression in the spectra across the series for each concentration of gold. For small amounts of gold, up to $x=0.75 \mathrm{mM}$, the difference spectra comprise a very broad singlet-like positive (upwards) component superimposed on a sextet-like negative (downwards) component. For larger amounts of $\mathrm{Au}(x>1.0 \mathrm{mM})$, the singlet component shrinks, becoming close to absent at $x=5.0 \mathrm{mM}$, while the sextet component flips to become a negative (downwards) component, which is also notably sharper than was the sextet component in the $x<1.0 \mathrm{mM}$ difference spectra.

For a more quantitative understanding of the changes across the series, the spectra were fitted using a quasiphenomenological model based on Voigt profiles - lineshapes corresponding to the summation of a Gaussian distribution of Lorentzian lines - to represent the broad lines that are typical of room temperature Mössbauer spectra of magnetite/maghemite nanoparticles. ${ }^{[31]}$ First the FeOx-C precursor material's spectrum was fitted using two Voigtian sextets, resulting in a very good fit (see Figure 3). Thereafter the remaining $\mathrm{FeOx}-\mathrm{Au}_{\mathrm{x}}$ spectra were fitted using three components: a subspectrum with parameters identical to that of the FeOx-C spectrum, with only its relative spectral area allowed to vary; and two other subspectra, both based on Voigtian profiles, one being essentially a sextet, and the other being best described as a 


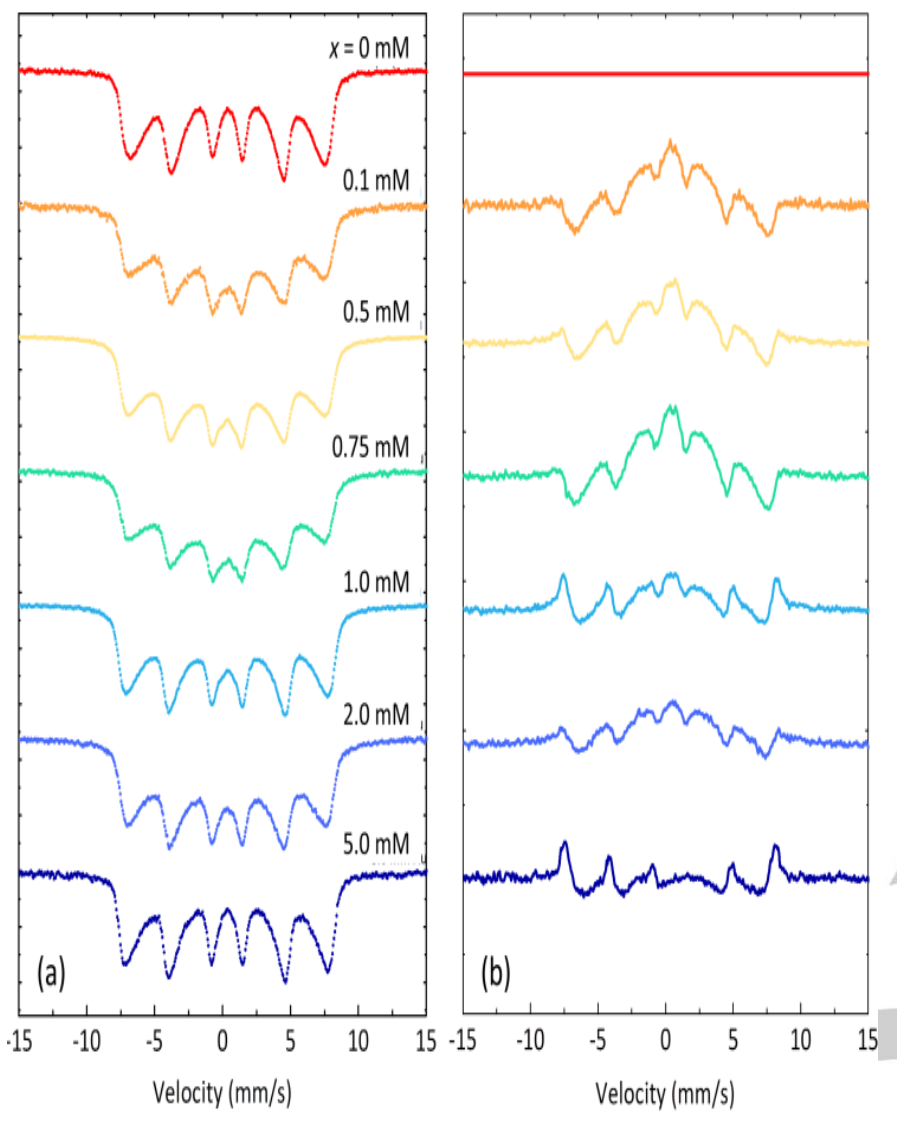

samples, as might be expected to occur at an interface between $\mathrm{FeOx}$ and Au phases.

\section{Magnetic hyperthermia measurements}

Magnetic heating curves were recorded for the $\mathrm{FeOx}-\mathrm{C}$ and FeOx-Au samples (see Figure 10) under non-adiabatic but linearheat-loss conditions, in accordance with established best practice. ${ }^{[23]}$ The observed heating rates were analysed using the corrected slope method, ${ }^{[23]}$ leading to estimates of both the intrinsic loss power (ILP), and the related extrinsic parameter, the specific absorption rate (SAR). These two parameters are related by:

$$
\text { ILP }\left[\mathrm{nHm}{ }^{2} / \mathrm{kg}\right]=S A R[\mathrm{~W} / \mathrm{kg}] / H^{2}[\mathrm{kA} / \mathrm{m}]^{2} f[\mathrm{kHz}]
$$

where $H$ is the amplitude of the sinusoidally varying applied magnetic field $H \sin (\omega t+\varphi)$, where $\omega=2 \pi f, \varphi$ is a constant, and $f$ is the frequency, and where the units of the different quantities are noted in square brackets. For the data shown in Figure 10a, $H=6.6 \mathrm{kA} / \mathrm{m}$ and $f=967 \mathrm{kHz}$.

The fitted ILP values (Figure 10b) show a marked peak in the vicinity of $x=0.75 \mathrm{mM} \mathrm{HAuCl}_{4}$. The peak ILP value is ca. 3 times greater than the ILP measured for either the precursor $\mathrm{FeOx}-\mathrm{C}$ nanoparticles, or for the higher concentration $\mathrm{FeOx}-\mathrm{Au}_{\mathrm{x}}$, $x \geq 2.0 \mathrm{mM}$ samples, and, at ca. $2.1 \mathrm{nHm}^{2} / \mathrm{kg}_{\mathrm{FeOx}}$, is comparable to the ILP values measured in the best commercially available materials to date. ${ }^{[24]}$

Figure 8. (a) Mössbauer spectra measured at room temperature for increasing amounts of gold in the FeOx-Aux samples, from $x=0$ (the iron oxide only sample, FeOx-C) to $x=5.0 \mathrm{mM}$. (b) Mössbauer 'difference spectra' obtained by subtracting the $\mathrm{FeOx}-\mathrm{C}$ spectrum from the $\mathrm{FeOx}-\mathrm{Au}_{\mathrm{x}}$ spectra. These spectra provide a model-independent visual indication of how the Au-containing $x>0$ spectra differ from that of the precursor FeOx.

broad quadrupole split doublet (see Figure 9a). The fitted parameters confirm the visual indication that there is a change in behaviour of the material over the range of $x$ from 0 to $5.0 \mathrm{mM}$, most notably in the area and splitting of the additional sextet component (Figure 9b).

Although it is difficult to be definitive, the Mössbauer data point to some interesting possible scenarios to explain the behaviour. First, there is clearly a difference between even the lowest $\mathrm{Au}$ concentration sample, $\mathrm{FeOx}-\mathrm{Au}_{0.1}$, and the precursor iron oxide $\mathrm{FeOx}-\mathrm{C}$. This is most likely to be a result of the additional heating and processing that the $\mathrm{FeOx}-\mathrm{Au}_{\mathrm{x}}$ samples were exposed to. One possibility is that some of the FeOx nanoparticles were oxidised from magnetite to maghemite during this step. The mean isomer shift of the samples trended towards a slightly lower value of $\bar{\delta}_{R T}=0.36 \pm 0.01 \mathrm{~mm} / \mathrm{s}$ across the series, which lends some weight to this hypothesis. The additional sextet component might also be a manifestation of this, as magnetite and maghemite have different mean hyperfine fields. Second, the presence of the doublet component is interesting, as it implies a less magnetic environment for some of the $\mathrm{Fe}$ atoms in the 

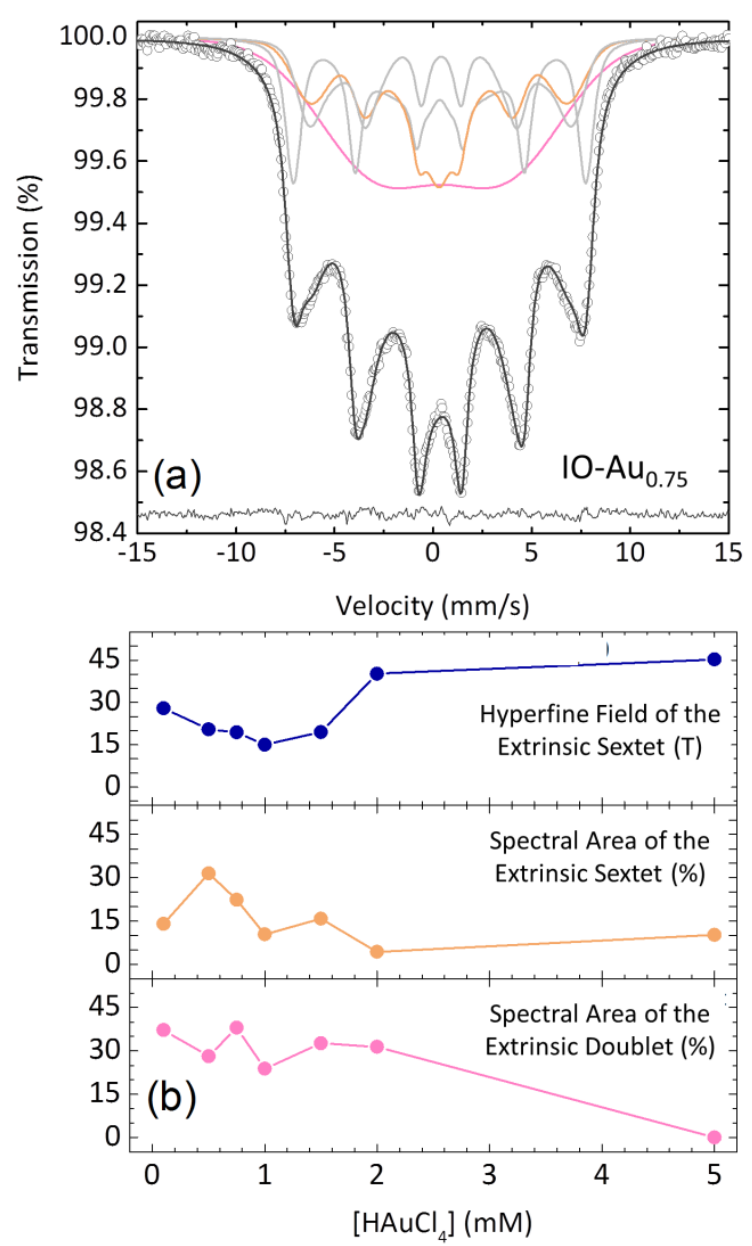

Figure 9. (a) Representative fit to the Mössbauer spectrum of sample FeOxAuo.75 using a quasi-phenomenological model. The constrained subcomponents of the initial FeOx-C spectrum are shown in grey, with additional ('extrinsic') subcomponents highlighted in orange (sextet) and pink (doublet). (b) Variation of some of the fitted Mössbauer parameters as a function of the $\mathrm{HAuCl}_{4}$ concentration $x$ : the percentage spectral areas of the extrinsic doublet and sextet components, and the mean hyperfine field $H_{h f}$ (in Tesla) of the extrinsic sextet component.
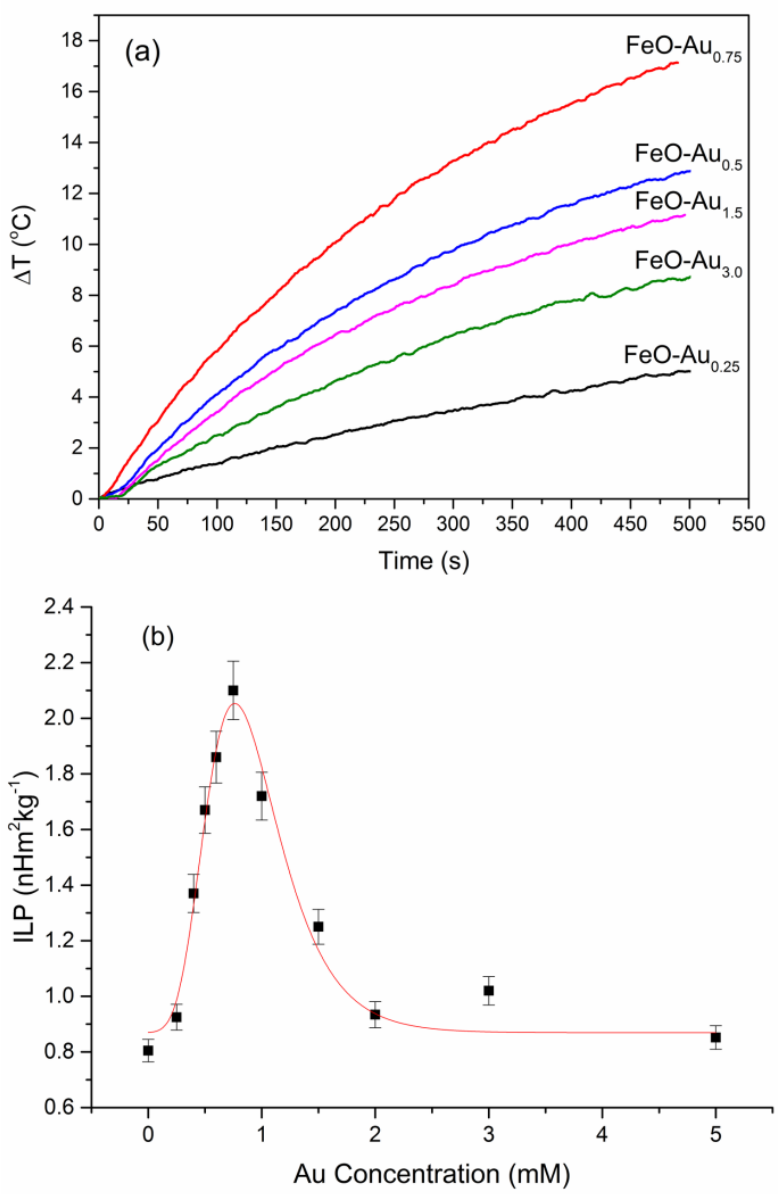

Figure 10. (a) Magnetic heating curves generated for representative $\mathrm{FeOx}-\mathrm{Au}_{\mathrm{x}}$ nanocomposites, and (b) the corresponding intrinsic loss parameters across the series, illustrating a ca. $3 x$ increase in heating capacity in the vicinity of $x=0.75$ $\mathrm{mM}$.

The data obtained in Figure $10 \mathrm{~b}$ is remarkable and unexpected. To the best of our knowledge, there are no previous reports in the literature of enhanced magnetic heating effects in iron oxide nanoparticles as a result of post-production treatment of any kind, let alone the incorporation of the nanoparticles into a composite with another phase entirely. However, in retrospect we can speculate that the observed enhancement is associated with the nature of the interface between the $\mathrm{FeOx}$ and $\mathrm{Au}$ phases, and the nature of the growth of gold on iron oxide. A recent study of the formation of gold-magnetite heterogeneous nanoparticles is informative in this respect, as the authors report therein that the $\mathrm{Au}$ deposition is characterised by island-type three-dimensional growth on the iron oxide surfaces, followed by coalescence to form a thick coating on the individual particles that did not necessarily cover all the iron oxide surfaces. ${ }^{[10]}$

Such behaviour may be occurring here, as evidenced by the marked change above $x \approx 1.0 \mathrm{mM}$ in the polydispersity of the $\mathrm{Au}$ nanoparticles as measured by TEM (Figure 4), and the minimum at $x \approx 1.0 \mathrm{mM}$ in the Mössbauer hyperfine field of the observed extrinsic sextet component (Figure 9). Both effects may be 
indicative of a turning point at $x \approx 1.0 \mathrm{mM}$ where the nature of the Au nanoparticle growth shifts in character from a surface island growth to a more separate Au-only habit - the latter accounting for a return to the baseline magnetic heating characteristics for $x$ $\geq 2.0 \mathrm{mM}$ (Figure 10).

We have further demonstrated that this phenomenon arises from the formation of nanocomposite material by the analysis of a physical mixture of pre-synthesised iron oxide nanoparticles and gold nanoparticles. With concentrations of this mixture representative of $\mathrm{FeOx}-\mathrm{Au}_{0.75}$, we see no enhancement of the ILP. The physical mixture yielded an ILP of $0.822 \mathrm{nHm}^{2} / \mathrm{kg}_{\mathrm{FeOx}}$ which is comparable to the initial FeOx-C value of $0.805 \mathrm{nHm} / 2 / \mathrm{kg}_{\mathrm{FeO}}$.

That said, even if this is the explanation for the observed peak in the ILP at $x \approx 0.75 \mathrm{mM}$, it still leaves open the question of mechanism, for which, at present, we have no definitive answer.

\section{Conclusions}

In this work we have used an adapted Turkevich-style synthetic route to produce iron oxide-gold nanocomposites that exhibit an unexpected enhancement of the magnetic heating characteristics of the incorporated iron oxide nanoparticles. The enhancement effect is found to be highly dependent on the synthesis conditions, and we speculate that it may be related to the different growth habits of the gold nanoparticles as a function of the relative concentrations of the reactants.

The availability of gold surfaces in the material, and the ease with which gold can act as a covalent bonding site for therapeutic agents, including many small-molecule pharmaceuticals as well as many biomarkers and reporting agents such as fluorophores, is clearly beneficial in terms of the development of a robust and versatile platform for drug delivery. Coupled to this, the presence of the iron oxide nanoparticles opens the realistic prospect of being able to provide adjuvant hyperthermia at clinically relevant doses and in a targeted fashion.

As such, we believe that the observations reported here constitute a very positive outcome, with significant ramifications for the future biomedical application of iron oxide-gold nanocomposites both as multimodal imaging agents and as biocompatible theranostic materials.

\section{Experimental Section}

Materials: All chemicals and were used as received and without further purification. Iron(III) chloride hexahydrate $\left(\mathrm{FeCl}_{3} .6 \mathrm{H}_{2} \mathrm{O}\right)(99 \%)$, iron(II) chloride tetrahydrate $\left(\mathrm{FeCl}_{2} .4 \mathrm{H}_{2} \mathrm{O}\right)(98 \%)$ and tetramethylammonium hydroxide (TMAOH) $(99 \%, 25 \% \mathrm{w} / \mathrm{w}$ water) were purchased from Alfa Aesar. Ammonium hydroxide $\left(\mathrm{NH}_{4} \mathrm{OH}\right)(25 \%$ in water w/w), citric acid $(99 \%)$, trisodium citrate dihydrate and hydrogen tetrachloroaurate trihydrate $\left(\mathrm{HAuCl}_{4} .3 \mathrm{H}_{2} \mathrm{O}\right)$ were all purchased through Sigma Aldrich. All water used was distilled to $15 \mathrm{M} \Omega$.

Synthesis of iron oxide nanoparticles: Citrate coated iron oxide nanoparticles were synthesised via the co-precipitation of ferrous and ferric chloride salts. A 2:1:1 ratio of $\mathrm{Fe}$ (III): $\mathrm{Fe}$ (II): citric acid capping ligand was mixed under an inert atmosphere to prevent unwanted oxidation.
Specifically: $\mathrm{FeCl}_{3} .6 \mathrm{H}_{2} \mathrm{O}(4.44 \mathrm{~g}, 16.4 \mathrm{mmol})$ and $\mathrm{FeCl}_{2} .4 \mathrm{H}_{2} \mathrm{O}(1.632 \mathrm{~g}, 8.2$ mmol) were dissolved into $\mathrm{N}_{2}$ purged $\mathrm{H}_{2} \mathrm{O}(80 \mathrm{~mL})$, resulting in an orange solution. The temperature was then raised to $70^{\circ} \mathrm{C}$ under $\mathrm{N}_{2}$, and $\mathrm{NH}_{4} \mathrm{OH}$ $(20 \mathrm{~mL})$ was added, turning the solution immediately black, and held for 30 minutes. Citric acid $(4 \mathrm{~mL}, 0.5 \mathrm{~g} / \mathrm{mL})$ was added and the temperature was raised to $90^{\circ} \mathrm{C}$ under reflux for 60 minutes. The black solution was cooled to room temperature, washed with $\mathrm{H}_{2} \mathrm{O}$ and collected via a permanent magnet, producing a stabilised black ferrofluid.

Synthesis of iron oxide - gold nanocomposites: Using the presynthesised iron oxide $(\mathrm{FeOx})$ nanoparticles, it was possible to use the citrate binding of the $\mathrm{FeOx}$ as a reducing agent for hydrogen tetrachloroaurate, $\mathrm{HAuCl}_{4}$, in a manner akin to that of the Turkevich synthesis, with some slight modifications. ${ }^{[29]}$ Firstly, $\mathrm{HAuCl}_{4}(20 \mathrm{~mL})$ of varying concentration between $0.1-5.0 \mathrm{mM}$ was heated to boiling and the previously synthesised citrate stabilised $\mathrm{Fe}_{3} \mathrm{O}_{4}\left(10 \mathrm{~mL}, 5 \mathrm{mgmL}^{-1}\right)$ was added instantaneously to the yellow solution. This mixture was boiled for 15 minutes, after which the solution turned from yellow to black to deep red/brown. The solution was then cooled to room temperature, washed with $\mathrm{H}_{2} \mathrm{O}$, and collected with a permanent magnet. These particles were then classified as $\mathrm{FeOx}-\mathrm{Au} \mathrm{u}_{\mathrm{x}}$, where $x$ denoted the concentration of hydrogen tetrachloroaurate used. Eleven different hydrogen tetrachloroaurate concentrations were used ranging from $0.1 \mathrm{mM}$ to 5.0 $\mathrm{mM}$, respectively.

Particle size and morphology: Particle size and morphology was performed using a combination of transmission electron microscopy (TEM), dynamic light scattering (DLS), and both UV-vis and infra-red (IR) spectroscopy. TEM was performed using a JEOL 1200EX MKII TEM microscope using an accelerating voltage of $120 \mathrm{kV}$. TEM samples were prepared by aqueous liquid drop of as-synthesised ferrofluid onto perforated carbon grids. DLS was performed on the aqueous ferrofluid with a Malvern Zetasizer Nano, using $1 \mathrm{~mL}$ samples in a $4.5 \mathrm{~mL}$ plastic cuvette. Ultra-violet spectra were obtained on a Lambda 25 UV-Vis spectrometer from wavelengths $300-1000 \mathrm{~nm}$ with a step size of $0.5 \mathrm{~nm}$. The analyte was as-synthesised in an aqueous medium and recorded in a $4.5 \mathrm{~mL}$ cuvette. Infra-red spectroscopy was performed on a Perkin Elmer Spectrum $100 \mathrm{FTIR} / \mathrm{ATR}$ Spectrometer in the wavenumber range 600 $4500 \mathrm{~cm}^{-1}$.

Mössbauer spectroscopy: The chemical composition was assessed using room temperature ${ }^{57} \mathrm{Fe}$ Mössbauer spectroscopy. Freeze dried samples were mixed with sucrose using a pestle and mortar and gently packed into a $22 \mathrm{~mm}$ diameter, ca. $2 \mathrm{~mm}$ thick disk-shaped sample holder. Transmission Mössbauer spectroscopy was performed at room temperature using a ${ }^{57} \mathrm{Co}$ foil source embedded in a rhodium matrix with an initial activity of $25 \mathrm{mCi}$. The source was driven over a range of velocities from $-15 \mathrm{~mm} / \mathrm{s}$ to $+15 \mathrm{~mm} / \mathrm{s}$ via a SeeCo W302 spectrometer using a constant-acceleration drive with triangular reference signal. Data were accumulated in a SeeCo W202 detector with 1024 channels (unfolded) that was calibrated against the Mössbauer spectrum of a standard $\alpha$-Fe foil at room temperature. All spectra were fitted using the Recoil data analysis programme. ${ }^{[35]}$

X-ray spectroscopy: X-ray photoelectron spectroscopy (XPS) was obtained with a K-Alpha X-ray Photoelectron Spectrometer system using monochromatic aluminium K-alpha X-rays $(0.83386 \mathrm{~nm}, 1.4867 \mathrm{KeV})$. Energy-dispersive $\mathrm{x}$-ray (EDX) spectra were obtained on a Philips XL30ESEM microscope. The crystal structure was investigated using powder $x$-ray diffraction (PXRD) which was achieved on a STOE STADI $P$ transmission diffractometer using $\mathrm{Mo} \mathrm{K}_{\mathrm{a} 1}$ radiation $\left(17.48 \mathrm{keV}, \lambda \mathrm{K}_{\mathrm{a} 1}=\right.$ $0.7093 \AA$ ) at $50 \mathrm{kV}$ and $30 \mathrm{~mA}$. The $2 \theta$ scan was performed between $2.000^{\circ}$ and $50.015^{\circ}$ at steps of $0.495^{\circ}$ with a scan duration of $10 \mathrm{~s} / \mathrm{step}$. 
Magnetic heating: The intrinsic loss parameters (ILPs) of the samples were measured using a Magnetic Alternating Current Hyperthermia (MACH) system built by Resonant Circuits Limited (London). This instrument comprised a purpose-built 6-turn copper solenoid operating at $967 \mathrm{kHz}$ that produced a sinusoidally varying magnetic field of peak amplitude $6.6 \mathrm{kAm}^{-1}$. Thermal heating curves were recorded as a function of time on application of the radio frequency (RF) field. Samples comprising $500 \mu \mathrm{L}$ of fluid were placed into glass vials in the centre of the RF coil, and temperature variations were recorded by averaging the data from two Luxtron FOT fluoroptic probe thermometers (LumaSense Technologies, USA) immersed within the fluid.

\section{Acknowledgements}

We would like to thank EPSRC and the Agency of Science Technology and Research (A*STAR) Singapore for funding and the $A^{\star}$ STAR ARAP program for a studentship.

\section{Keywords: Iron Oxide $\bullet$ Gold $\bullet$ Nanoparticles $\bullet$ Nanostructures • Magnetic Hyperthermia}

[1] B. Hamm, T. Staks, M. Taupitz, R. Maibauer, A. Speidel, A Huppertz, T. Frenzel, R. Lawaczeck, K. J. Wolf, L. Lange, J. Magn. Reson. Imaging 1994, 4, 659-668.

[2] Q. A. Pankhurst, J. Connolly, S. K. Jones, J. Dobson, J. Phys. D Appl. Phys. 2003, 167, R167-R181.

[3] Q. A. Pankhurst, N. Thanh, S. Jones, J. Dobson, J. Phys. D Appl. Phys. 2009, 224001, 224001 (15pp).

[4] L. Thomas, L. Dekker, M. Kallumadil, P. Southern, M. Wilson, S. Nair, Q. A. Pankhurst, I. P. Parkin, J. Mater. Chem. 2009, 19, 65296535.

[5] A. K. Gupta, M. Gupta, Biomaterials 2005, 26, 3995-4021.

[6] N. T. Pourianazar, U. Gunduz, Biomed. Pharmacother. 2016, 78, $81-91$.

[7] R. Guzman, N. Uchida, T. M. Bliss, D. He, K. K. Christopherson, D. Stellwagen, A. Capela, J. Greve, R. C. Malenka, M. E. Moseley, et al., Proc. Natl. Acad. Sci. USA 2007, 104, 10211-10216.

[8] N. Gandra, D. Wang, Y. Zhu, C. Mao, Angew. Chem. Int. Ed 2013 52, 11278-11281.

[9] E. Bull, S. Y. Madani, R. Sheth, A. Seifalian, M. Green, A. M. Seifalian, Int. J. Nanomedicine 2014, 9, 1641-1653.

[10] M. Tian, D. Chen, Y. Sun, Y. Yang, Q. Jia, RSC Adv. 2013, 3, 22111-22119.

[11] W. Wu, Q. He, C. Jiang, Nanoscale Res. Lett. 2008, 3, 397-415.
[12] X. Qiu, Y. Zhou, X. Jin, A. Qi, Y. Yang, J. Mater. Chem. C 2015, 3, 3517-3521.

[13] M. Z. Iqbal, X. Ma, T. Chen, L. Zhang, W. Ren, L. Xiang, A. Wu, J. Mater. Chem. B 2015, 3, 5172-5181.

[14] X. Qiu, Q. Li, Y. Zhou, X. Jin, A. Qi, Y.-W. Yang, Chem. Commun 2015, 51, 4237-4240.

[15] H. Zhang, Q. S. Liu, C. L. Yang, J. Z. Lv, L. Q. Xie, M. J. Tang, Z. F Yue, Z. G. Wan, Food Anal. Methods 2013, 6, 933-940.

[16] J. L. Lyon, D. A. Fleming, M. B. Stone, P. Schiffer, M. E. Williams Nano Lett. 2004, 4, 719-723.

Q. H. Lu, K. L. Yao, D. Xi, Z. L. Liu, X. P. Luo, Q. Ning, J. Magn. Magn. Mater. 2006, 301, 44-49.

[18] T. T. Hien Pham, C. Cao, S. J. Sim, J. Magn. Magn. Mater. 2008 320, 2049-2055.

[19] I. Robinson, L. D. Tung, S. Maenosono, C. Wälti, N. T. K. Thanh, Nanoscale 2010, 2, 2624-2630.

[20] E. S. Krystofiak, E. C. Mattson, P. M. Voyles, C. J. Hirschmugl, R M. Albrecht, M. Gajdardziska-Josifovska, J. A. Oliver, Microsc. Microanal. 2013, 19, 821-834.

[21] A. P. Khandhar, R. M. Ferguson, H. Arami, K. M. Krishnan, Biomaterials 2013, 34, 3837-3845.

D. Ortega, Q. A. Pankhurst, Nanoscience 2012, 1, 60-88.

R. R. Wildeboer, P. Southern, Q. A. Pankhurst, J. Phys. D Appl. Phys. 2014, 47, 495003 (14pp).

M. Kallumadil, M. Tada, T. Nakagawa, M. Abe, P. Southern, Q. A Pankhurst, J. Magn. Magn. Mater. 2009, 321, 1509-1513.

C. B. Collins, R. S. McCoy, B. J. Ackerson, G. J. Collins, C. J. Ackerson, Nanoscale 2014, 6, 8459-72.

S. A. Curley, P. Cherukuri, K. Briggs, C. R. Patra, M. Upton, E. P. Dolson, P. Mukherjee, J. Exp. Ther. Oncol. 2008, 7, 313-26.

S. J. Corr, M. Raoof, Y. MacKeyev, S. Phounsavath, M. A. Cheney, B. T. Cisneros, M. Shur, M. Gozin, P. J. McNally, L. J. Wilson, et al., J. Phys. Chem. C 2012, 116, 24380-24389.

R. S. McCoy, S. Choi, G. Collins, B. J. Ackerson, C. J. Ackerson, ACS Nano 2013, 7, 2610-2616.

[29] J. Turkevich, P. C. Stevenson, J. Hillier, Discuss. Faraday Soc. $1951,11,55-75$ 
[32] G. M. da Costa, C. Blanco-Andujar, E. De Grave, Q. A. Pankhurst, J. Phys. Chem. B 2014, 118, 11738-46.

[33] J. Fock, L. K. Bogart, D. Gónzalez. Alonso, J. I. Espeso Martinez, M. F. Hansen, C. Frandsen, Q. A. Pankhurst, On the 'Centre of Gravity' Method for Measuring the Composition of

Magnetite/Maghemite Mixtures, or the Stoichiometry of MagnetiteMaghemite Solid Solutions, via ${ }^{57} \mathrm{Fe}$ Mössbauer Spectroscopy Unpublished Manuscript, 2017.
[34]

B. Cao, Y. Zhu, L. Wang, C. Mao, Angew. Chem. Int. Ed 2013, 52, $11750-11754$.

[35]

K. Lagarec, D. G. Rancourt, Nucl. Instruments Methods Phys. Res. Sect. B Beam Interact. with Mater. Atoms 1997, 129, 266-280. 


\section{Entry for the Table of Contents}

Layout 1:

\section{FULL PAPER}

The addition of gold nanoparticles in the post-production treatment of iron oxide nanoparticles to form a nanocomposite material can improve magnetic heating properties of the iron oxide when subject to an alternating magnetic field.

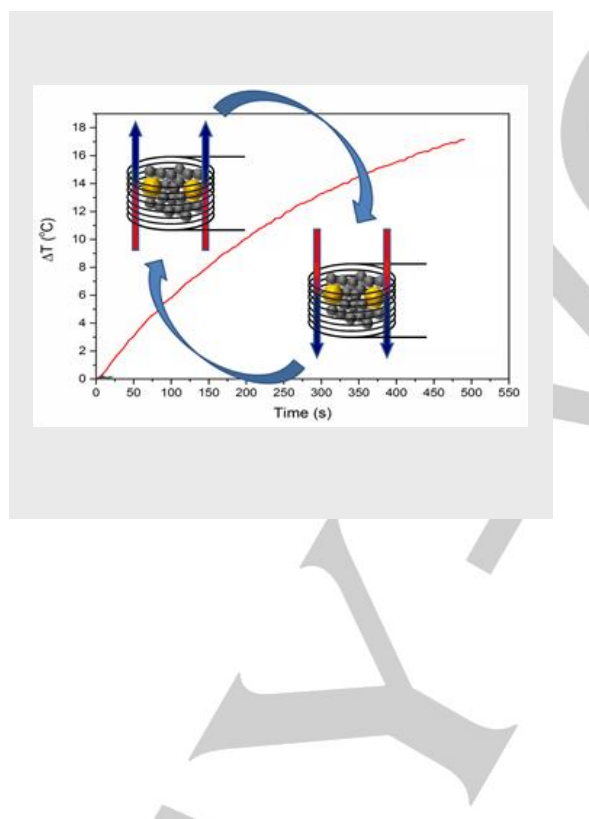

Magnetic Hyperthermia

Gavin Bell*, Lara K. Bogart, Paul Southern, Malini Olivo, Quentin A. Pankhurst and Ivan P. Parkin*

Page No. - Page No.

Enhancing the magnetic heating capacity of iron oxide nanoparticles through their post-production incorporation into iron oxide-gold nanocomposites 